Stanley Davis MBChB FFA(SA),

Richard Erskine $M B C h B$ FFA(SA), Michael F.M. James MBChB PhD FFARCS

\section{A comparison of spinal and epidural anaesthesia for hip arthroplasty}

Spinal and epidural anaesthesia were compared in 65 patients undergoing hip arthroplasty, with regard to the degree of sensory and motor blockade, cardiovascular effects, operating conditions, the dose of propofol required to produce satisfactory hypnosis, and complications. Epidural anaesthesia was successful in 30 patients using an initial dose of $15 \mathrm{ml}$ of $0.5 \%$ bupivicaine, and spinal anaesthesia in 32 patients, using $4 \mathrm{ml}$ $0.5 \%$ isobaric bupivicaine. The two techniques were similar with regard to the level of sensory blockade $\left(T_{8}\right)$, degree of hypotension and perioperative haemorrhage. Differences occurred in the degree of motor blockade (mean Bromage score of 1 in the spinal group vs 3.86 in the epidural group) $(P<0.05)$, time to achieve maximal cephalad spread $(13 \mathrm{~min}$ in the spinal group vs 21 min in the epidural group) $(P<$ $0.05)$ and the dose of propofol required to produce adequate hypnosis $\left(1.95 \mathrm{mg} \cdot \mathrm{kg}^{-1} \cdot \mathrm{hr}^{-1}\right.$ in the spinal group vs 2.89 $\mathrm{mg} \cdot \mathrm{kg}^{-1} \cdot \mathrm{hr}^{-1}$ in the epidural group) $(P<0.05)$. Only seven patients required urethral catheterization in this spinal group compared with 14 in the epidural group $(P<0.05)$. Spinal anaesthesia also proved advantageous by providing better operating conditions for the surgeon, with a lower incidence of patient movement.

Cette étude compare la rachi-anesthésie et l'anesthésie péridurale chez 65 patients subissant une arthroplastie de la hanche. Les paramètres évalués sont le niveau du bloc de conduction sensitif, la qualité du bloc moteur, les effets cardiovasculaires, la facilité d'accès chirurgical, les complications et

\section{Key words}

ANAESTHESIA: regional, epidural, spinal;

ANAESTHETICS, LOCAL: bupivacaine;

SURGERY: orthopaedic.

From the Department of Anaesthesia, Groote Schuur Hospital and University of Cape Town, Observatory, 7925, Republic of South Africa.

Address correspondence to: Dr. S. Davis.

Accepted for publication 22nd February, 1992. la quantité de propofol nécessaire pour maintenir une hypnose au cours de l'intervention. L'anesthésie péridurale est réalisée avec succès chez 30 patients en utilisant une dose initiale de $15 \mathrm{ml}$ de bupivacaine $0,5 \%$. La rachi-anesthésie est faite avec succès chez 32 patients en utilisant $4 \mathrm{ml}$ de bupivacaïne $0,5 \%$ isobare. Les deux techniques sont associées à un bloc de conduction sensitif de niveau $T_{\&}$ La chute de pression et les saignements périopératoires sont comparables avec une technique ou l'autre. Le bloc moteur moyen est de l à l'échelle de Bromage avec la rachi-anesthésie comparativement à 3,86 avec l'anesthésie péridurale $(P<0,05)$. La migration céphalade maximale de l'agent anesthésique est plus rapide avec la rachi-anesthésie $(13 \mathrm{~min}$ versus $21 \mathrm{~min} ; P<0,05)$. La dose de propofol nécessaire pour maintenir l'hypnose est de $1,95 \mathrm{mg} \cdot \mathrm{kg}^{-1} \cdot \mathrm{h}^{-1}$ chez les patients du groupe rachi-anesthésie comparativement à $2,89 \mathrm{mg} \cdot \mathrm{kg}^{-1} \cdot \mathrm{h}^{-1}$ chez les patients $d u$ groupe péridurale $(P<0,05)$. Sept patients du groupe rachianesthésie versus 14 patients du groupe péridurale ont besoin de cathétérisme vésical $(P<0,05)$. La rachi-anesthésie est associée à moins de mouvements des patients durant la chirurgie, et de ce fait elle permet un meilleur accès chirur. gical.

The complications of spinal and epidural anaesthesia, as well as the relative advantages of the two techniques, have recently been comprehensively reviewed. ${ }^{1,2}$ The choice between techniques has also been the subject of recent editorial comment. ${ }^{3}$ Although both techniques are now widely used to provide anaesthesia for hip arthroplasty, there has been no controlled trial of the comparative merits of either technique for this particular procedure, which is often carried out in elderly patients and is associated with a considerable perioperative blood loss ${ }^{4}$ and with a high incidence of postoperative thromboembolism. Furthermore, iatrogenic bacteraemia must be avoided, as an infected prosthesis carries a severe morbidity. This prospective randomized study sets out to evaluate efficacy, cardiovascular effects, acceptability and complications of epidural vs spinal anaesthesia for hip arthroplasty. 


\section{Methods}

The study was approved by the Ethics Committee of the University of Cape Town.

Sixty-five patients scheduled for primary hip arthroplasty were entered into the study after giving informed written consent. Patients with fixed cardiac output states, a bleeding disorder, skeletal abnormalities of the spine or neurological disease were excluded. All patients received premedication with oral diazepam $0.15 \mathrm{mg} \cdot \mathrm{kg}^{-1}$, two hours preoperatively. In the induction suite a Plasmalyte B preload of $12 \mathrm{ml} \cdot \mathrm{kg}^{-1}$ was given, a supine baseline blood pressure was recorded using a non-invasive, blood pressure monitor (Dinamap-Critikon), whereafter patients were prepared and draped in the sitting position. Using random numbers, patients were then allocated to either an epidural or spinal group.

In the epidural group the epidural space was located at $\mathrm{L}_{3-4}$ using an 18-gauge Tuohy needle and loss of resistance device (Portex). Bupivicaine $0.5 \%, 15 \mathrm{ml}$, was injected through the Tuohy needle as two increments a $5-\mathrm{ml}$ test dose, followed four minutes later by $10 \mathrm{ml}$ injected over $60 \mathrm{sec}$. A catheter was then introduced into the epidural space for supplementary bupivicaine if required. In the spinal group lumbar puncture was performed in the $\mathrm{L}_{3-4}$ interspace using a 25-gauge spinal needle, and $4 \mathrm{ml}$ of isobaric bupivicaine $0.5 \%$ was injected over ten seconds.

The Dinamap was set to measure and record at oneminute intervals, then the patients were placed in the supine position and after 15 min the Dinamap was reset to record at five-minute intervals, which was continued for the duration of the procedure.

The cephalad spread of sensory blockade was measured by determing the upper level of analgesia to pinprick at five-minute intervals until a maximum height was reached. The degree of motor blockade of the lower limbs was measured at five-minute intervals using a Bromage score ${ }^{5}(1=$ complete paralysis; $2=$ movement of feet only; 3 = slight flexion of knees; 4 = full flexion of knees) for $30 \mathrm{~min}$ or until complete paralysis occurred. In the epidural group injection of the test dose was taken as time zero.

Hypnosis was provided with an infusion of propofol, initiated at a dose of $2 \mathrm{mg} \cdot \mathrm{kg}^{-1} \cdot \mathrm{hr}^{-1}$ and adjusted according to individual response, to abolish verbal communication and movement. Intraoperative fluid therapy consisted of crystalloid (Plasmalyte B), colloid (Haemaccel) for intraoperative hypotension, defined as systolic blood pressure $<66 \%$ of baseline, and whole blood or packed red cells if blood loss was predicted to result in a haemoglobin concentration of $<8.5 \mathrm{~g} \cdot \mathrm{dl}^{-1}$. Blood loss was assessed by weighing swabs and measuring the volume suctioned from the operation site.
TABLE I Demographic data - spinal vs epidural anaesthesia

\begin{tabular}{llll}
\hline & & Spinal & \multicolumn{1}{l}{ Epidural } \\
\hline Age yr & Mean & $59.4 \pm 14.8$ & $59.7 \pm 16.3$ \\
& Range & $18-82$ & $18-83$ \\
\multirow{2}{*}{ Weight kg } & Mean & $67.8 \pm 14.3$ & $67.4 \pm 8.8$ \\
& Range & $47-90$ & $40-93$ \\
\multirow{2}{*}{ Sex } & Male:Female & $13: 19$ & $13: 17$ \\
\hline
\end{tabular}

Oxygen saturation, measured throughout, using pulse oximetry (Oxyshuttle-Critikon), was maintained $>90 \%$ using oxygen-enriched air via a ventimask.

Sensory and motor blockade were monitored at 15 min intervals after surgery until there was a two-segment regression of sensory block and the minimum Bromage score had increased by one point.

Any unacceptable patient movement reported by the surgeon, who had no knowledge of the anaesthetic technique used, was noted and the anaesthetic was deemed unacceptable. Further assessment included the measurement of postoperative blood loss via a portovac drain during the first $24 \mathrm{hr}$ and the need for urinary catheterization.

Results were analysed using Student's t, Fischer's exact or Willcoxon rank sum tests where appropriate. $P$ $<0.05$ was considered statistically significant.

\section{Results}

Thirty-two patients were randomized to the epidural and 33 to the spinal group. The groups were similar with regard to age, sex and weight (Table I). One patient in the spinal group (sensory level $\mathrm{L}_{2}$ ) and two in the epidural group (unilateral left-sided block for right-sided surgery and no sensory deficit after $40 \mathrm{~min}$ ) had an unsatisfactory level of sensory blockade and, following the institution of general anaesthesia, were not subjected to further investigation.

While the degree and duration of sensory blockade were similar (Table II), there was a marked difference in the degree of motor blockade, as indicated by the Bromage score. All patients in the spinal group had a Bromage score of 1 and all but one patient in the epidural group had a score of 4 , with the one exception having a score of 3 . Two patients in the spinal and nine in the epidural group $(P<0.05)$ exhibited an unacceptable degree of lower limb movement intraoperatively. There was no difference in the degree of hypotension, intraoperative or postoperative blood loss (Table III). The propofol required by the epidural group $2.89 \pm 1.5$ $\mathrm{mg} \cdot \mathrm{kg}^{-1} \cdot \mathrm{hr}^{-1}$ was greater than in the spinal group 1.95 $\pm 0.8 \mathrm{mg} \cdot \mathrm{kg}^{-1} \cdot \mathrm{hr}^{-1}(P<0.05)$.

Seven patients in the spinal and 14 in the epidural 
TABLE II Sensory blockade - spinal vs epidural anaesthesia

\begin{tabular}{llll}
\hline & & Spinal & Epidural \\
\hline $\begin{array}{c}\text { Mean height of } \\
\text { sensory block }\end{array}$ & Mean & $\mathrm{T}_{8} \pm 2.2$ & $\mathrm{~T}_{8} \pm 2.15$ \\
$\begin{array}{c}\text { Time to maximum } \\
\text { height (min) }\end{array}$ & & $\mathrm{T}_{4}-\mathrm{T}_{12}$ & $\mathrm{~T}_{4}-\mathrm{T}_{12}$ \\
$\begin{array}{c}\text { Time to 2 segment } \\
\text { regression (hr) }\end{array}$ & $13 \pm 7$ & $21 \pm 4^{*}$ \\
\hline
\end{tabular}

$* P=0.05$

TABLE III Degree of hypotension, intraoperative blood loss and postoperative drainage: spinal vs epidural anaesthesia

\begin{tabular}{lcc}
\hline & Spinal & Epidural \\
\hline $\begin{array}{l}\text { \% decrease of systolic } \\
\text { blood pressure }\end{array}$ & $18.5 \pm 11.1$ & $20.3 \pm 9.3$ \\
$\begin{array}{l}\text { Intraoperative blood loss }(\mathrm{ml}) \\
\text { Postoperative blood loss }(\mathrm{ml})\end{array}$ & $850 \pm 497.8$ & $961 \pm 696.6$ \\
\hline
\end{tabular}

group required catheterization for urinary retention after surgery $(P<0.05)$. In the spinal group catheterization occurred $4.2 \pm 1.7 \mathrm{hr}$ after transfer to the postoperative high care unit compared with $4.7 \pm 2.3 \mathrm{hr}$ in the epidural group $(P>0.05)$.

\section{Discussion}

The study has shown a number of advantages of spinal anaesthesia over the epidural technique, viz: more rapid cephalad spread, increased motor blockade, decreased dose of propofol to produce hypnosis, less patient movement and urinary retention requiring catheterization. Furthermore, this study has not demonstrated decreased haemodynamic stability with the spinal route.

The study was performed at a peripheral orthopaedic hospital, where anaesthetic staffing is such that the use of blind assessors to the quality of anaesthesia, could not be considered. We believe that measurement of both sensory and motor blockade is objective enough so as not to detract from the merit of this unblinded study.

Patients in the epidural group were given an initial dose of $15 \mathrm{ml} 0.5 \%$ bupivicaine with the facility to increase the dose via the epidural catheter. This volume has previously proved to be adequate for hip arthroplasty. ${ }^{4}$ In this study an acceptable sensory level was obtained in all but two patients. One patient developed a unilateral block and the other had no appreciable loss of sensation after $40 \mathrm{~min}$, casting doubt on the site of injection. Given this, and the tendency to compartmentalization of the epidural space, ${ }^{6}$ it appeared both futile and dangerous to increase the volume of bupivicaine via the catheter, and general anaesthesia was instituted.
A major reason advanced for the preference of the extradural route is the threat of hypotension caused by the sudden and very extensive vasomotor block associated with the intrathecal route. ${ }^{7}$ Numerous studies have demonstrated this phenomenon, but these have all been in obstetrical patients. ${ }^{8.9}$ Furthermore, comparison of the haemodynamic stability of the epidural route is purely historical. ${ }^{7}$ This study has demonstrated an equal degree of haemodynamic stability in patients undergoing total hip replacement.

An important finding was the decreased incidence of urinary retention resulting in catheterization. The sympathetic outflow to the lower urinary tract promotes urine storage. When intravesical pressure reaches a critical level, stretch receptors in the bladder wall initiate efferent impulses that reach the spinal cord via pelvic nerves. Such activation elicits parasympathetic efferent release of acetycholine, with detruser contraction and internal sphincter relaxation. Urinary retention is due to complex effects on peripheral and central neurogenic mechanisms controlling the micturition reflex. These would include autonomic blockade, estimated to be three times longer than two segment regression time. ${ }^{10}$ Catheterization occurred well within this period in both groups. Epidural anaesthesia produces only partial motor blockade as opposed to the more intense block affected by the spinal technique. It is possible that this variability produced by epidural anaesthesia also applies to autonomic blockade, with a relatively intact sympathetic supply. This is the first description of this difference between the extradural and intrathecal route in the induction of central neural blockade. The implications are important in the context of hip arthroplasty. Sepsis following hip arthroplasty usually results in the rejection of the prosthesis. Bacteraemia and metastatic infection may follow urethral instrumentation " and the need for catheterization increases the incidence of deep sepsis following hip replacement to $6.2 \%^{11}$ - compared with an infection rate of $0.5 \%$ when operations are performed in clean air. ${ }^{12}$ Therefore, spinal anaesthesia, with an incidence of catheterization similar to general anaesthesia, ${ }^{13}$ appears to offer an advantage over the epidural technique in this respect.

The shorter time taken to achieve maximal cephalad spread in the spinal group is inconsequential when seen in the total context of the rigorous preparation and draping routine required for hip arthroplasty in a clean air enclosure.

The Bromage score has been criticized as a qualitative indicator of motor blockade and does not evaluate the block quantitatively. ${ }^{14}$ In this study, however, there was good correlation between the different degree of motor blockade, as measured by the Bromage score, and the 
difference in the number of patients exhibiting an unacceptable degree of movement. Two patients in the spinal group, with an initial Bromage score of 1 , exhibited unacceptable lower limb movement intraoperatively in spite of adequate sensory block, indicating relatively brief motor blockade. The remainder of the spinal group of patients had complete relaxation throughout the procedure.

While the improved motor function produced by epidural anaesthesia may be advantageous in terms of venous stasis, the absence of motor function produced by spinal anaesthesia produces better operating conditions for the surgeon. Furthermore, excessive patient movement is not merely of nuisance value, but could have deleterious consequences were the patient to move during the seating of a cemented prosthesis. Fortunately this did not occur in this study.

A further difference between the groups was the higher dose of propofol required by patients in the epidural group. Similar results have been reported previously. Valli and Rosenberg provided additional analgesia to 11 of 15 patients who received epidural anaesthesia, whereas only one of 15 patients who received spinals had these requirements. ${ }^{15}$ In a large retrospective study comparing continuous spinal to continuous epidural anaesthesia in elderly patients, there was no difference in the requirement for intraoperative sedative or analgesic drugs. However, the epidural group in that study had received more premedication. ${ }^{16}$ This is the first prospective study demonstrating less sedative requirements in patients undergoing hip surgery. The higher rate of propofol infusion required by the epidural group probably reflects the need for deeper hypnosis in an attempt to provide similar operating conditions, and abolish the excess movement resulting from retained motor function.

In summary, spinal anaesthesia provided better operating conditions, and required less supplemental hypnosis to produce satisfactory conditions. A further, important advantage was that it resulted in less urethral instrumentation. Whether the increased degree of motor function provided by the epidural technique imparts protection against DVT requires further investigation.

\section{References}

1 Gavino GC. Rationale for spinal anaesthesia. Int Anaesthesiol Clin 1989; 27: 8-12.

2 Hurley RJ. Complications of spinal anaesthesia. Int Anaesthesiol Clin 1989; 27: 51-5.
3 Wildsmith JAW. Intrathecal or extradural: which approach for surgery? Br J Anaesth 1987; 59: 397-8.

4 Keith I. Anaesthesla and blood loss in total hip replacement. Anaesthesia 1977; 32: 444-50.

5 Bromage PR. A comparison of the hydrochloride and carbon dioxide salt of lidocaine and procaine in epidural analgesia. Acta Anaesthesiol Scand 1965; 17: Supplement XVI; 55-69.

6 Husemeyer RP, White DC. Topography of the lumbar epidural space. Anaesthesia 1980; 35: 7-11.

7 Crawford JS. There is only a limited place for spinals in obstetrics. Acta Anaesthesiol Belg 1988: 39; 181-4.

8 Russel IF, Holmquist ELO. Subarachnoid analgesia for caesarean section. Br J Anaesth 1987; 59: 347-53.

9 Abouleish El. Epinephrine improves the quality of spinal hyperbaric bupivicaine for Caesarean section. Anesth Analg 1987; 66: 395-400.

10 Phillipe $A C$, Durart $M D$. Intraspinal analgesia and urinary bladder dysfunction. Acta Anaesthesiol Belg 1988; 39: 163-7.

11 Wroblweski $B M$. Urethral instrumentation and deep sepsis in total hip replacement. CORR 1980; 146: 209-12.

12 Charnley J. Acrylic Cement in Orthopaedic Surgery. Edinburgh \& London, Livingstone 1970; 111.

13 Walts $L F$, Kaufman RD, Moreland JR, Weiskopf $M$. Total hip arthroplasty. An investigation of factors related to postoperative urinary retention. CORR $1985 ; 194$ : 280-8.

14 Axelsson $K$, Hallgren $S$, Widman $B$, Johannsson A, Olstrin PO. A new method for measuring motor block in the lower extremities. Acta Anaesthesiol Scand 1985; 29: 72-8.

15 Valli $H$, Rosenberg PH. Effects of three anaesthesia methods on haemodynamic responses connected with the use of thigh tourniquet in orthopaedic patients. Acta Anaesthesiol Scand 1985; 29: 142-7.

16 Sutter PA, Gamulin Z, Forster A. Comparison of continuous spinal and continuous epidural anaesthesia for lower limb surgery in elderly patients. A retrospective study. Anaesthesia 1989; 44: 47-50. 